\title{
ERRATUM
}

\section{Erratum zu: Ein neuer Ansatz zur Optimierung des Bilanzausgleichs in einem Gasmarktgebiet}

\author{
Uwe Gotzes $^{1}$ \\ Online publiziert: 24. September 2019 \\ ๑) Springer Fachmedien Wiesbaden GmbH, ein Teil von Springer Nature 2019

\section{Erratum to: A New Approach to Optimize Balancing in a Gas Market Area}

\section{Erratum zu:}

Z Energiewirtsch 2019

https://doi.org/10.1007/s12398-019-00257-6

Im Abschn. 4.2 wurde eine Autorkorrektur falsch ausgeführt. Die Online Version des Artikels wurde korrigiert.

Nachfolgend der korrekte Textabschnitt:

Im dritten und vierten Beispiel (siehe Abb. 2c und d) gibt es vier FN und ein VN (V) sowie ein NOM (N). Der Fluss über die Kante $\mathrm{F} \rightarrow \mathrm{V}$ liegt immer im Intervall [0.5,2] und der Fluss über die Kante $\mathrm{E} \rightarrow \mathrm{V}$ liegt immer im Intervall $[0,2]$. Damit ergeben sich die Verlagerungspotenziale $\mathrm{p}_{\mathrm{F}, \mathrm{E}}=1$ und $\mathrm{p}_{\mathrm{E}, \mathrm{F}}=0,5$.

Die Online-Version des Originalartikels ist unter https://doi.org/ 10.1007/s12398-019-00257-6 zu finden.

Uwe Gotzes

uwe.gotzes@open-grid-europe.com

1 Open Grid Europe GmbH, Kallenbergstr. 5, 45141 Essen, Deutschland 